\title{
Total Synthesis of Indoxamycins A, C, and F
}<smiles>CC#CCC(C)(C(C)=O)C1(C)C=CC(=O)C=C1</smiles>

A
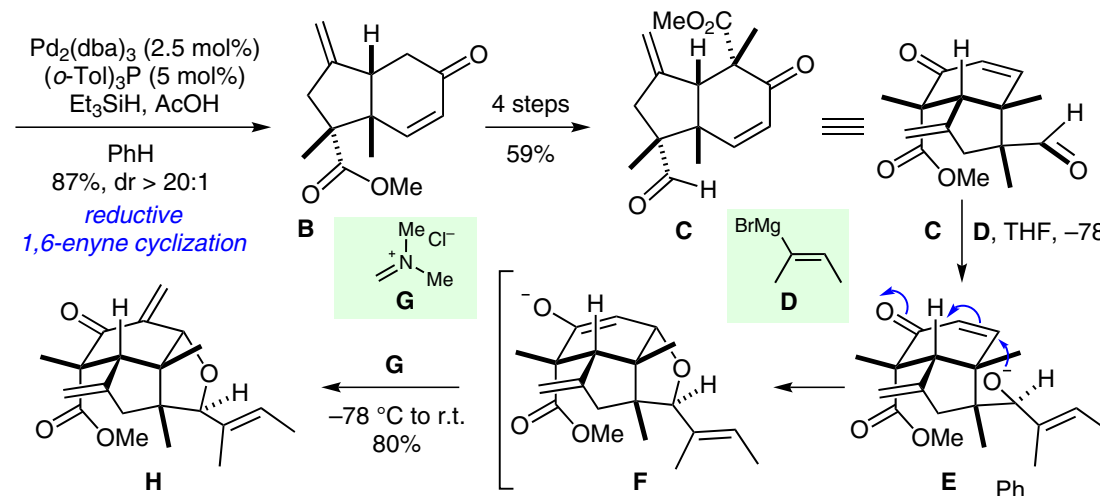

1,6-enyne cyclization
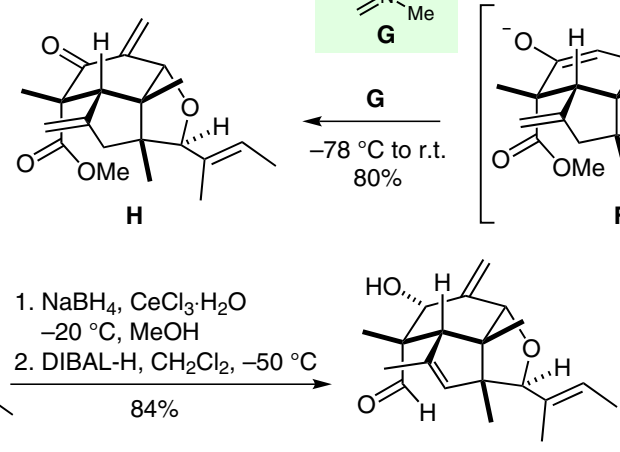

1. $\mathrm{NaBH}_{4}, \mathrm{CeCl}_{3} \cdot \mathrm{H}_{2} \mathrm{O}$

$-20^{\circ} \mathrm{C}, \mathrm{MeOH}$

2. DIBAL- $\mathrm{H}, \mathrm{CH}_{2} \mathrm{Cl}_{2},-50^{\circ} \mathrm{C}$
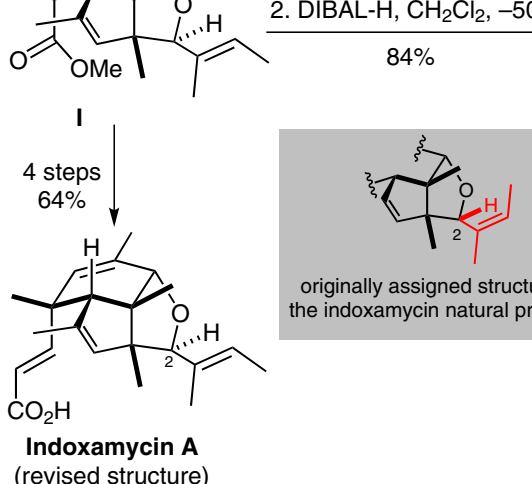

originally assigned structure of the indoxamycin natural products
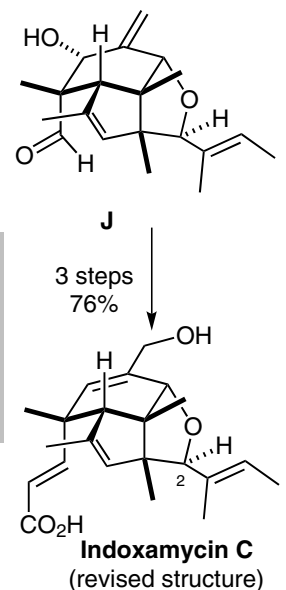

Gategory

Synthesis of Natural

Products and

Potential Drugs

Key words

indoxamycins

polyketides

reductive 1,6-enyne cyclization

palladium
Significance: In 2009, a Japanese research group reported the isolation of a novel class of natural products, the indoxamycins. These marine-derived polyketides are characterized by a highly substituted tricyclic core, bearing six contiguous stereogenic centers, three of which are quaternary. This work describes not only the total synthesis of indoxamycin A, C, and F, but led also to a stereochemical revision. This finding is in agreement with the total synthesis and the resulting structural reassignment of another member of the family, indoxamycin B (O. F. Jeker, E. M. Carreira Angew. Chem. Int. Ed. 2012, 51, 3474; Synfacts 2012, 8, 593).
Comment: A salient feature of the presented synthesis is a highly selective palladium-catalyzed reductive 1,6-enyne cyclization to access bicycle $\mathbf{B}$ in excellent yield. After four more steps, a tandem 1,2-Grignard addition-oxa-Michael-methenylation $(\mathbf{C} \rightarrow \mathbf{H})$ followed by double-bond isomerization provides rapid entry to common intermediate $\mathbf{I}$. From this branching point, all three target molecules could be synthesized in a few transformations (3-4 steps) and high overall yield. The spectra of all three natural products matched the reported isolation data, therefore confirming the hypothesis of a stereochemical misassignment at $\mathrm{C} 2$ and of the double-bond geometry. 